\title{
EFFECT OF CORIADRUM SATIVUM ON EXPERIMENTALLY IDUCED HEPATOTOXICITY OF CARBON TETRACHLORIDE IN RATS
}

\author{
Nabila Zein 1*, Essam Abd Elghani ${ }^{2}$ \&EmanTalat ${ }^{1}$ \\ 1Biochemistry Division, Chemistry Department, Faculty of Science, Zagazig University \\ 2Chemistry Department, Faculty of Science, Zagazig University
}

\section{ARTICLE INFO}

Key words:

Coriandrum sativum (CS) ; Liver fibrosis; Anti-oxidant activity ; Haematology.
ABSTRACT

Objective: The aim of this study was to investigate the possible antifibrotic effect and antioxidant role of Coriandrum sativum (CS) extract against Carbon tetrachloride (CCL4)induced liver fibrosis in adult male rats. Method: The extracted CS was proved by phytochemical analysis (thin layer chromatography (TLC)). This study was carraidout on (72) rats these animals were divided into six groups of (72) rats The first group is negative control group. The second group is Positive control group .The third group is Preventive group. The forth group is Therapeutic group. The fifth group is Silymarine group. The sixth group is Combination group.Result: The TLC analysis revealed the presence of some important polyphenolic compounds as Kaempferol ,Quercetin , 3 '_OMe quercetin , 4 OMe quercetin, Acacetin and some of phenolic acids e.g Vanillic acid, p - Coumaric acid, Cis - Ferulic acid, Trans - Ferulic acid which could be responsible for the anti-oxidant activity . Treatment with CS significantly decreased the elevated plasma aspartate aminotransferase (AST) and alanine aminotransferase (ALT) while increased the albumin level. It also inhibited the formation of lipid peroxidative products Malondialdehyde (MDA) and nitric oxide (NO) during $\mathrm{CCl}_{4}$ administration. Moreover, treatment $\mathrm{CS}$ extract brought significant restoration of the haematological parameters to values that were comparable to those of the control. CS, treatment enhances the liver and kidney health (which confirmed by histopathological studies). Conclusion: The present study indicates that the coriandrum sativum extract possess significant anti-fibrotic and antioxidant activity in liver against experimental hepatotoxicity and nephrotoxicity in vivo. Increasing CS consumption is recommended, especially in cases of heavy contaminants and hepatic and renal disorder.

\section{INTRODUCTION}

Liver is an organ of paramount important as it plays an essential role in maintaining the biological equilibrium of vertebrates. The spectrum of its functions include, metabolism of carbohydrates, lipids and proteins, blood coagulation and immunomodulation ${ }^{1}$.It also has a great capacity to detoxificate toxic substances and synthesize useful ones. Therefore, damage 
on the liver inflicted hepatotoxic agent is of grave consequences . Hepatic diseases represent the major cause of human mortality in the world, they are characterized by a progressive evolution from steatosis to chronic hepatitis, fibrosis, cirrhosis and hepatocellular carcinoma ${ }^{2}$. A majar cause of these disorders is due to exposure to different environmental pollutants and xenobiotics such as alcohol, paracetamol, carbontetrachloride and thioacetamide ${ }^{3}$ The kidneys possess the common xenobiotic metabolizing enzymes, localized in proximal tubular cell ${ }^{4}$.Anumber of environmental contaminants, chemicals and drugs dramatically alter the structure and function of the kidneys 5 .

Carbontetrachloride

(CCl4) an

industrial solvent, cleaner and degreaser. It is proved to be hepatotoxic as well as nephrotoxic to human ${ }^{\mathbf{6}, 7}$. The initial step in biotransformation of $\mathrm{CCl} 4$ is reductive dehalogenation and by formation trichloromethyl and trichloromethylperoxyl radicals ${ }^{\mathbf{8}}$.As electrophils, these free radicals initiate the lipid peroxidation process and induced damage and dysfunction of DNA and proteins ${ }^{\mathbf{9}, 10}$. Also, CCl4 upregulates the gene expression of many inflammatory markers ${ }^{11}$, mean -while down regulates the gene expression of many antioxidant enzymes triggering an oxidative stress ${ }^{\mathbf{1 2}}$.

Conventional or synthetic drugs used in the treatment of liver diseases are inadequate and can have serious adverse effects. Thus there is a world-wide trend to return to traditional medicinal plants to treat liver ailments ${ }^{13}$. Anti-fibrotics from natural products used in traditional medicine may reduce the risk of toxicity and maintain the therapeutic effectiveness when the drug is used clinically $\mathbf{1 4 ,} \mathbf{1 5}$. Various phytochemical components especially polyphenols such as flavonoids, phyenyl propanoids, phenolic acids, tannins and others. Polyphenolic compounds are widely distributed in plants and known to be excellent antioxidants in vitro and have the capacity to scavenge free radicals and protect antioxidant defence ${ }^{\mathbf{1 6}}$.

Since dietary polyphenols have been reported to be inversely associated with lipid peroxidation and cytotoxicity, an attempt was made to study the effects of the extracts of Coriandrum sativum on the activities of antioxidant enzymes in $\mathrm{CCl} 4$ treated liver. Coriander is available throughout the year providing a fragrant flavour, originated around the Mediterranean and is cultivated mainly in the tropical areas. The seeds contain an essential oil "linalool" a monoter penoid and the leaves contain good amount of caffeic acid, ferulic acid, gallic acid and chlorogenic acid ${ }^{17}$. The seeds and aerial parts of the plant are extensively used in traditional system of medicine for various ailments like spasm ${ }^{18}$ rheumatism, neuralgia, gastric complaints ${ }^{\mathbf{1 9}}$ bronchitis, diarrhea, dysentery, gout, dyspepsia and giddiness. Moreover, coriander has been shown biological activities as anti-tumor, chemopreventive and anti-inflamatory agents and may play arole in regulating the activity and/ or expression of certain enzematic systems that are included in apaptosis, tumor promotion, intracellular signal transduction or xenbiotic metabolizing enzymes ${ }^{20}$.

The plant is known to possess hypoglycemic ${ }^{21}$ antibacterial, antifungal ${ }^{22}$ free radical scavenging and lipid peroxidation activities ${ }^{\mathbf{2 3}}$.

The search for novel natural antioxidants of plant origin has ever since increased. It is not known which constituents of plant are associated in reducing the risk of chronic diseases, but antioxidants appear to play a major role in the protective effect of plant medicine. The present study was designed to investigate in vivo antioxidant activities of ethanolic extract of Coriander. Results were compared to a standard antioxidant drug silymarin. Silymarin (SMN), an extract of Silybummarianum, has well established hepatoprotective properties. It is a standardized mixture of 
flavonolignans including silybinin, isosilybinin, silydianin and silychristin. SMN effectively scavenges free radicals, antagonizes lipid peroxidation, and stabilizes cell membranes ${ }^{\mathbf{2 4}}$. At the molecular level, SMN stimulates RNA and protein synthesis leading to faster regeneration, repair, and renovation after liver injury. SMN also modulates inflammation and TNF- $\alpha$ production in vitro and in vivo ${ }^{\mathbf{2 5}}$ and binds to hepatocellular receptors, preventing toxins from binding to those sites, therefore, it seems of interest to evaluate the antioxidant activity and hepato-protective effect of coriander sativium in comparison with silymarin against CCI4 - induced hepatic injury in rats.

\section{MATERIAL AND METHODS \\ Materials:}

Carbon tetrachloride and chemical kits for biochemical analysis were obtained from El-Gomhorya Pharmaceutical Company, Cairo, Egypt.

\section{Plant Material:}

The fresh leaves and stem of coriander overall, were purchased from the local market at Cairo, Egypt. The plant sample were kindly identified and proved by Herbarium unit of Potany Department faculty of Science Zagazege University . The plant samples were airdried for 10 days and powdered. The powdered samples were placed in air tight container for future use.

\section{Extract Preparation:}

The dried and powdered plants $(2 \mathrm{~kg})$ were extracted successively with mixture of ethanol: water $(3: 1)$ in a soxhlet extractor for 48 hours at $60^{\circ} \mathrm{C}$. After extraction, the solvent was evaporated to dryness at 50$55^{\circ} \mathrm{C}$ using a rotary evaporator. Finally, the lyophilization of the dried extract was done to yield the Coriander ${ }^{26}$ The extract was stored at $4^{\circ} \mathrm{C}$ in avacum for future till the analysis of different parameters.

\section{Animals:}

Adult male Sprague-Dawely rats $(\mathrm{n}=72)$ weighing 180-260 gm were purchased from Animal House of the National Research Center (NRC), Dokki, Giza, Egypt. They were kept individually in stainless steel wire bottomed cages at room temperature $\left(25 \pm 2{ }^{\circ} \mathrm{C}\right)$ under $12 \mathrm{hr}$ dark light cycle. Animals were fed balanced diets. Rats had free access to food and water. They were used after acclimatization period of one week.

\section{Phytochemical analysis:}

The chromatographic profiles were developed for ethanolic extract using in triplicates for the identification of the polyphenols by paper chromatpgraphyas ${ }^{27}$ The Polyphenol separation included the isolation and identification of (a) Flavonoids (b) Phenolic Acids (c) Glycoflavones. The standard analytical procedures involving interaction with diagnostic reagents and paper chromatographic separation of compounds and their UV/Visible spectroscopic studies including hypsochromic and bathochromic shifts with reagents such as $\mathrm{AlCl} 3$, $\mathrm{AlCl} / \mathrm{HCl}, \quad \mathrm{NaOMe}, \mathrm{NaOAc}$ and $\mathrm{NaOAc} / \mathrm{H} 3 \mathrm{PO} 3$ were followed for the identificationof flavonoids and other phenolics. The identities of all the compounds were confirmed by cochromatogaphy (paper and thin-layer chromatography) with authentic samples 28.

\section{Behaviour and toxic effects:}

Different groups of rats were treated with graded doses of the coriandrum sativum extract $(100 \mathrm{mg}, 200 \mathrm{mg}, 500 \mathrm{mg}$ and 750 $\mathrm{mg}, \mathrm{p.o})$. One group was maintained as control and was given $0.5 \%$ Tween- 80 . They were observed continuously for $1 \mathrm{~h}$ for any gross behavioural changes and death, if any and then, intermittently for the next $6 \mathrm{~h}$, and then again at $24 \mathrm{~h}$ after dosing with C. sativum extract ${ }^{29}$.

\section{Experimental Design:}

Animals were randomly assigned to six groups each of twelve rats as follow:

Group 1: Negative control group, Rats injected i.p. with saline once daily for 7 days. 
Group 2: Positive control group, Rats injected i.p. with $\mathrm{CCl} 4$ in a dose of $0.5 \mathrm{ml} / \mathrm{kg}$ b.wt i.p once daily for 7 days ${ }^{30}$. Group 3: Preventive group, Rats were injected i.p with coriander extracted dose of $200 \mathrm{mg} / \mathrm{kg}$ b.wt orally by gavages at the beginning of the experiment, at the second day Rats were injected i.p. with $\mathrm{CCl} 4$ in a dose of 0.5 of $\mathrm{ml} / \mathrm{kg}$ b.wt i.p once daily for 7 days, and then Rats were received orally by gavages the coriander extracted in a dose of $200 \mathrm{mg} / \mathrm{kg}$ once daily for 15 days. Group 4: Therapeutic group, Rats were injected i.p. withCCl4 in a dose of $0.5 \mathrm{of}$ $\mathrm{ml} / \mathrm{kg}$ b.wt i.p once daily for 7 days, and then Rats were received orally by gavages the coriander extracted in a dose of 200 $\mathrm{mg} / \mathrm{kg}$ once daily for 15 days.

Group 5: Silymarine group, Rats were injected i.p. withCCl4 in a dose of $0.5 \mathrm{of}$ $\mathrm{ml} / \mathrm{kg}$ b.wt i.p once daily for 7 days, and then rats were received silymarin in a dose of $25 \mathrm{mg} / \mathrm{kg}$ b.wt orally by gavages once daily for 15 days. ${ }^{29}$

Group 6: Combination group, Rats were injected i.p. with $\mathrm{CCl} 4$ in a dose of 0.5 of $\mathrm{ml} / \mathrm{kg}$ b.wt i.p once daily for 7 days, and then rats were received orally by gavages a combined dose of $200 \mathrm{mg} / \mathrm{kg}$ the coriander extracted and $25 \mathrm{mg} / \mathrm{kg}$ silymarine once daily for 15 days.

\section{Blood collection and tissue homogenate:}

At the end of $15^{\text {th }}$ day, blood samples were collected from the retro-orbital vein plexus and direct cardiac puncture, under ether anesthesia. Whole blood used for haematogram was collected into tubes containing the anticoagulant, ethylene diamine tetra-acetic acid (EDTA) while samples for biochemical analysis were collected into plain sample tubes. Sera samples were separated by centrifugation at $600 \times \mathrm{g}$ for $15 \mathrm{~min}$. and were stored in the $-80{ }^{\circ} \mathrm{C}$ freezer before they were analyzed.

Liver and kidney tissues were excised from each rat and divided into 2 parts, part of liver tissue from each group was collected in sample tubes contains phosphate buffer saline (PBS) pH 7.4; for biochemical analysis, The second part of tissue from each group was preserved in $10 \%$ neutral formalin solution for histological examination.

\section{Biochemical Analysis:}

The biochemical analysis include determination of ALT and AST levels ${ }^{31}$, liver malondialdehyde level ${ }^{32}$, serum albumin level ${ }^{33}$, liver nitric oxide level ${ }^{34}$ and haematological parameters were determined by auto haematology analyzer (Diatron Abacus 380)

\section{Histopathological Study:}

Liver and kidney of the sacrificed rats were taken and immersed in $10 \%$ formalin solution. The specimens were then trimmed, washed and dehydrated in ascending grades of alcohol. Then cleared in xylol, embedded in paraffin, sectioned (4-6 microns) and stained with Heamtoxylin and Eosin for histopathological examination ${ }^{35}$.

\section{Statistical Analysis:}

Statistical analysis of data was performed by using SPSS 14.0 version using T-test (2- tailed) was applied to compare between groups and one way analysis of variance (ANOVA) according to the method described by ${ }^{\mathbf{3 6}}$ followed by post-hoc test using Graphpad Prism-5 software. numerical data were expressed as mean $\pm \mathrm{SD}, \mathrm{P}$ values $<0.05$ were considered to be statistically significant.

\section{RESULTS}

\section{Extraction of plant:}

Corainder sativum $(2 \mathrm{~kg}$ ) after undergoing extraction yielded deeply green paste $(60 \mathrm{~g})$ of the extract.

\section{Phytochemical consitituents and toxicity studies:}

The extract revealed the presence of various phytoconstituents of polyphenolslike flavonoids and phenolic Acids.The flavonoids that were identified are kaempferol, quercetin,3'-OMe quercetin,4'-OMe quercetin and acacetin as shown in table (1). The phenolic acids that were identified vanilic acid, ferulic acid (cis and trans form) and p-coumaric acid as shown in table (2). 


\section{Toxicity study:}

In acute toxicity, no mortality was observed up to a dose of $750 \mathrm{mg} / \mathrm{kg}$ body weight.

\section{Biochemical result:}

There was significant decrease in the level of ALT, AST, MDA and NO and significant increase appeared in albumin level in combination, preventive, therapeutic and silymarine groups compared to positive control group as shown in Table (3) and Figs 1,2,3,4 and 5.

\section{Hematological result:}

There was significant increasing in RBC counts, $\mathrm{Hb}$ concentration, palatelete counts and total WBC counts in combination, preventive, therapeutic and silymarine groups compared to positive control group as shown in Table (4)

\section{Histopathological results :}

The negative control groups showed normal central vein (star) with radiating cords of normal hepatocytes showing central uniform nuclei, and finely granular cytoplasm (Figure7a). The positive control rat liver showing dilated congested hepatic sinusoids (star), early hepatocellualr dysplasia with nuclear pleomorphism and hyperchromasia (arrow head), with occasional binucleation of hepatocytes (bold arrow) (Figure 6b).Interestingly, treatment with coriander sativum extract reduced most of the pathological alterations induced by CCL4 in rats. The combined group rat liver showing slightly dilated central veins (star) with normal liver cords and sinusoids (Figure 6c). The preventive group rat liver showing slightly dilated hepatic sinusoids (star), normal hepatocytes (Figure 6d). The therapeutic group rat liver showing dilated portal tract with mild portal fibrosis (bold arrow) surrounded by normal hepatocytes (Figure 6e). The silymarine rat liver showing dilated congested hepatic sinusoids (star), and areas of hemorrhage (bold arrow) (Figure 6f).

Microscopically, kidneys of rat from negative control group showing normal renal tubules lined by single layer of cuboidal epithelium (Figure 7a) .kidneys of rat from the positive control group showing diffusely infiltrating chronic nonspecific inflammatory cellular infiltrates mainly lymphocytes, (Figure 7b). kidneys of rat from the preventive group showing normal renal cortex with normal glomerulus (arrow) with normal capillary tufts, and surrounded by normal renal tubules (Figure 7c) . Kidneys of rat from the sylimarin treated group showing renal medulla with near normal renal tubules apart from mild cloudy swelling of renal tubular epithelium (Figure 7d). Kidneys of rat from the therapeutic group showing renal medulla with normal renal tubules and mild interstitial inflammation (Figure 7e). Kidneys of rat from the combined group showing normal renal tubules lined by single layer of cuboidal epithelium with rounded uniform nuclei (Figure 7f) .

\section{DISCUSSION}

Coriandeum sativum(Coriander) of family Umbelliferae is a well known plant derived from the traditional system of medicine in India and a native of Mediterranean region $^{37}$. CS is considered as a rich source of biologically active compounds mainly polyphenolic compounds. It has been reported to possess diuretic, carminative, digestive, anthelmintic, antioxidant ${ }^{\mathbf{2 2}}$, antibacterial and antifungal activities $\mathbf{3 8}^{\prime}$. An interest has increased in naturallyoccurring antioxidants that can be used to protect from oxidative stress damage induced by $\mathrm{CCl}_{4}{ }^{39}$. This is largely due to the afford ability of these products along with no or fewer side effects they produced as compared to conventional drugs. CS is commonly used as a food ingredient, is claimed to be useful for various ailments via its antioxidant activity ${ }^{\mathbf{4 0}}$. The present studies indicate that Polyphenol separation by co-chromatogaphy (paper and thin-layer chromatography) included the isolation and identification flavonoids and Phenolic Acids. In Coriander leaves the flavonoids that were identified are quercetin, kaempferol and and aldehydes, which are common in coriander structures, 
phospholipids, phytosterols, flavonoids and active phenol are found to help fighting inflammation and free radicals. Coriander contains about $1 \%$ volatile oil mainly linalool, 20\% oleic, petroselinic and linolenic fatty acids, monoterpene ,hydrocarbons, up to $26 \%$ flavonoid glycosides 41. Quercetin is found in abundance in onions, apples, broccoli and berries. Thus coriander leaves, rich in quercetin, can be an important food source for the prevention of chronic degenerative diseases. The flavonol quercetin $(3,3$ ', 4', 5, 7- pentahydroxy flavone) is one of the most abundant dietary flavonoids. Quercetin and other flavonoids have been shown to modify eicosanoid biosynthesis (antiprostanoid and anti-inflammatory responses), protect low density lipoprotein (LDL) from oxidation (prevention of atherosclerotic plaque formation) and promote relaxation of cardiovascular smooth muscle (antihypertensive, antiarrythemic effects) ${ }^{28}$. In addition, flavonoids have been shown to have antiviral and anticarcinogenic properties ${ }^{42}$. Generally, some flavonoids exert a stimulatory action on transcription and gene expression of certain antioxidant enzymes that play an important role against oxidative insults ${ }^{\mathbf{4 3}}$. Flavonoids can activate or inhibit the biotransformation and resulting toxicity of drugs ${ }^{\mathbf{4 4 , 4 5}}$. The current study demonstrated that coriander contain several phenolic acids that were identified vanilic acid, ferulic acid (cis and trans form) and p-coumaric acid as can be seen from Table 2. Vanillin, a polyphenolic compound, in CS was found to be effective in preventing DNA fragmentation caused by $\mathrm{CCl} 4{ }^{46}$.Phenolic compound ferulic acid has added health benefits as it battles cancer. Ferulic acid is the predominant bound phenolic form. The fact that ferulic acid could be identified in $\mathrm{CS}$, emphasizes their potential role in the fight against cancer ${ }^{\mathbf{4 6}}$.

Carbon tetrachloride (CCL4) is a potent hepato and nephro toxin that mimics oxidative stress in many physiological situations37. Hepatotoxicity produced by $\mathrm{CCl} 4$ seems to be mediated by reactive metabolite trichloro methyl free radical (.CCl3) formed by the hemolytic cleavage of $\mathrm{CCl} 4$ or even by more reactive species trichloro methyl peroxy free radical (Cl3COO.) formed by the reaction of . $\mathrm{CCl} 3$ with $\mathrm{O} 2$ caused membrane damage of hepatocytes and resulted in centrilobular necrosis 48 .Meanwhile, some studies showed that the nephrotoxic effects of $\mathrm{CCl} 4$ are associated with free radical production ${ }^{9}$.These free radicals attack microsomal lipids leading to its peroxidation and also covalently bind to microsomal lipids and proteins. This results in the generation of reactive oxygen species (ROS), which includes the superoxide anionO $2, \quad \mathrm{H} 2 \mathrm{O} 2$ and the hydroxyl radical ${ }^{49}$.

The current study revealed that $\mathrm{CCl} 4$ administration caused severe hepatic damage through a substantial increment in the blood levels of hepatic biochemical markers like ALT and AST ${ }^{7}$. When liver cell membrane is damaged, a variety of enzymes normally located in the cytosol are released into blood stream like, (AST) and (ALT) are found in higher concentrations in the cytoplasm and AST in particular also exists in mitochondria. AST is found in the liver, cardiac muscle, skeletal muscles, pancreas, kidney and others, meanwhile, ALT level is highest in the liver and therefore, it appears to be more sensitive test for hepatocellular damage than AST 50. However, the elevated activities of AST and ALT are indicative ofcellular leakage and loss of functional integrity of cell membranes in liver ${ }^{1}$.

Our data in table 3 and fig 1 and 2 showed that CS has significant decrease on the elevation of plasma levels of ALT and AST due to its antioxidant effect as it was observed that CS lowered ALT and AST activities by $51.6 \%$ and $51.1 \%$ of combination group, by $43.04 \%$ and 43.6 $\%$ of preventive group ,by $30.09 \%$ and 
$31.8 \%$ of therapeutic group and by 18.8 $\%$ and $21.4 \%$ of silymarine group all groups in comparison with positive group . This is in agreement ${ }^{37}$ who reported that pretreatment with CS before introduction of $\mathrm{CCl} 4$ had significantly reduced the elevated plasma enzyme significantly reduced the elevated plasma enzyme indicating a hepato- protectant activity of CS via its antioxidant activity quenches ROS produced by $\mathrm{CCl} 4$, reserves antioxidant enzymes and restores their levels and protects cellular organelles from CCl4 damage such as cell membrane, lysosomes, mitochondria and microsomes .Moreover ${ }^{29}$ observed that administration of CS to rats induced a significant decrease in the levels of the above enzymes which may be due to the stabilization of plasma membrane as well as repair of hepatic tissue damage caused by CCL 4 and this is supported by the view that serum levels of transaminases return to normal with the healing of hepatic parenchyma and regeneration of hepatocytes .

$\mathbf{5 1}$ reported that, silymarin has an antihepatotoxic activity against CCL4 induced hepatotoxicity in rats. Silymarin protects liver against the increase in serum ALT and AST. Silymarin is known to have Hepato-protective effect ${ }^{\mathbf{5 2}}$.

CCL4 caused decrease in total serum protein that might be due to the decrease in the number of hepatocytes which in turn,may result in decreased hepatic capacity to synthesize protein ${ }^{\mathbf{8}}$.Also Significant decrease in serum albumin had been associated with active cirrhosis and biliary liver damages ${ }^{\mathbf{5 3}}$. The present study in table 3 fig 3 showed asignificant decrease in serum albumin due to oxidative stress by CCL4 on hepatocyte to synthesize albumin. Our data reflect the antioxidant activity and hepatoprotective effect by elevation of serum albumin by $33.3 \%, 25.9 \%, 18.5 \%$ and $11.1 \%$ in combination, preventive, therapeutic and silymarine groups respectively in comparison with positive group. This is in agreement ${ }^{\mathbf{5 4}}$ who revealed that the administration of coriander and silymarin pre-treatment effectively prevented these alterations of serum albumin and maintained the antioxidant status. In another study ${ }^{\mathbf{8}}$ who stated that the treatment of aqueous leaf extract of Cnidoscolus aconitifolius (CA) can make the restoration of the level of albumin level the hepatoprotective nature of CA.

Malondialdehyde (MDA) is a major reactive aldehyde that appears during the peroxidation of biological membrane polyunsaturated fatty acid ${ }^{\mathbf{5 5}}$. Therefore, the hepatic content of MDA is used as an indicator of liver tissue damage ${ }^{\mathbf{5 6}}$. MDA, an end product of lipid peroxidation, is widely used as a marker of lipid peroxidation. Lipid peroxidation (LP) is one of the main manifestations of oxidative damage and has been found to play an important role in toxicity and carcinogenicity. It is well documented that $\mathrm{CCl} 4$ enhanced LP $\mathbf{5 7}, \mathbf{5 8}$ that is an indication of free radical mediated toxi city. Free radicals are known to attack the highly unsaturated fatty acids of the cell membrane and induce lipid peroxidation that is considered a key process in many pathological events induced by oxidative stress ${ }^{59}$. In the present study, MDA was found to be significantly higher in the animals treated with $\mathrm{CCl} 4$ alone suggesting that this agent has a significant effect on LP and supported the earlier finding ${ }^{\mathbf{6 0}, \mathbf{6 1}}$.

CCL4 induced oxidative stress caused enhanced lipid peroxidation. Combination ,Preventive ,therapeutic and silymarine groups showed significant degree of protection against oxidative damage caused by CCL4 by decreasing lipid peroxidation in comparison with positive control rats, as it was observed that CS has lowered the MDA level by $72.9 \%$, $66.1 \%, 49.8 \%$ and $30.5 \%$ in liver combination, preventive, therapeutic and silymarine groups in comparison with positive group. Hence, it may be possible that CS decreases lipid peroxidation level due to its antioxidant effect. 
Moreover 56who reported that the increase in (MDA) levels in liver was due to enhanced lipid peroxidation leading to tissue damage and failure of antioxidant defense mechanisms to prevent formation of excessive free radicals in $\mathrm{CCl} 4$ induced hepatotoxicity in rats. Treatment with ethanol extract of $C S$ significantly reversed these changes, and it may be possible that the mechanism of hepatoprotection by ethanol extraction of CSis due to its antioxidant effect.

54 stated that Lipid peroxidation refers to the oxidative stress degradation of lipid in which (MDA) is one of its end products. It mostly affects polyunsaturated fatty acids causing tissue damage ${ }^{\mathbf{6 2}}$ and the elevation in MDA levels in both liver and kidney of irradiated rats may be due to the enrichment of cell membrane with polyunsaturated highly oxidizable fatty acids . The administration of C.S decreases in MDA level in irradiated rat liver and kidney , because of coriander has antioxidant property and it is valid to consider that it might be capable of protecting the liver and kidney tissues from irradiation induced injury changes ${ }^{63}$. The antioxidative property of coriander is related to the large amounts of tocopherols, carotenoids and phospholipids ${ }^{64}$, which act through different mechanisms.

29 reported that most of the hepatotoxic chemicals including CCL4 dameged liver mainly by inducing lipid peroxidation directly or indirectly. Therefore, the hepatic content of MDA is used as indicator of liver tissue damage involving a series of chain reactions. It has been accepted that lipid peroxidation of hepatocyte membranes is one of the principal causes of CCL4 -induced hepatotoxicity, and is mediated by the production of free radical derivatives of CCL4. Thus administration of Coriandeum sativum significantly decrease hepatic MDA concentration by reducing hepatic lipid peroxidation which may be due to an enhancement of antioxidant enzymes, these antioxidant enzyme system played an important role in the defence of cells against oxidative insults and ameliorates the effect of the extracts from C.S, on oxidative stress induced by CCL4. ${ }^{\mathbf{6 5}}$ Silymarin can prevent the absorption of toxins into the hepatocytes by occupying the binding sites as well as inhibiting many transport proteins at the membrane. These actions along with antiperoxidative property make silymarin a suitable candidate for the treatment of toxic liver diseases ${ }^{\mathbf{6 6}}$.

The excessive production of nitric oxide (NO) in the cell may be due to viral or bacterial infections and can promote pathogenesis by promoting oxidative stress, tissue injury and even cancer ${ }^{67}$.Nitric oxide (NO) is produced by macrophages and it plays an important role in tumor conditions ${ }^{\mathbf{6 8}}$.

The generation of NO by the inducible nitric oxide synthase (iNOS) played a key role in the cytokine-mediated cell destruction ${ }^{69}$. In the current study, the ingestion of $\mathrm{CCl} 4$ significantly increased NO suggesting that $\mathrm{CCl} 4$ preferentially affects macrophage functions. It is well documented that excess ROS, a condition referred to as oxidative stress, is considered to be a major contributor to cell injury, although many studies have shown that higher levels of ROS can also activate specific genetic programs in various cells 70.

Furthermore a significant inhibition on NO formation that might be due to its antiinflammatory effect, as it was observed that CS lowered the NO level by $59.03 \%$ $, 30.04 \%, 15.95 \%$ and $9 \%$ in liver of combination preventive, therapeutic and silymarine groups in comparison with positive group.

It is notable that, Several flavonoids, including quercetin resulted in a reduction in the ischemia-reperfusion injury by interfering with inducible nitric-oxide synthase activity. Nitric oxide reacts with free radicals, thereby producing peroxynitrite can directly oxidize LDL, resulting in irreversible damage to the cell 
membrane. When flavonoids are used as antioxidants, free radicals are scavenged and, therefore can no longer react with nitric oxide, resulting in less damage Coriander is also reported to be a chelating agent and reported to be effective as pharmaceutical agents in removing heavy metals ${ }^{71}$.

49 found that treatment with Grape Vitisvinifera Seed (GSE) extract showed significant improvements in the antioxidant enzymes, oxidative stress markers, nucleic acids content and gene expression as indicated by the reduction of NO levels, this is due to GSE has the chemical properties of bioflavonoids, in terms of the availability of the phenolic hydrogens as hydrogen donating radical scavengers and singlet oxygen quenchers, predicts their antioxidant activity.

The Hematological alterations of acute and chronic experimental inflammation in adult rats were monitored because of their diagnostic significance. It was demonstrated clearly that $\mathrm{CCl} 4$ administration produced pancytopenia (a generalized reduction in the cellular elements in the blood) as shown by erythrocytopenia, thrombocytopenia and leucocytopenia in the blood as evidenced by the reduction in the RBC, haemoglobin, platelets and total WBC counts, which believed that this reduction in the formed elements in the blood under stress ${ }^{72}$.

73 consistent erythrocyte damage is presumed to be related to direct oxidative injury to the red cells by the chemicals or to the pitting function of the spleen. It may be assumed that the free radicals resulting from CCL4 metabolism caused liver injury corroborated by the increased erythrocyte osmotic fragility which has also been reported to increase during oxidative stress ${ }^{74}$.Thrombocytopenia is a common finding in advanced liver cirrhosis and is usually related to the congestive splenomegaly of portal hypertension and possibly to inadequate thrombopoietin synthesis by the failing liver ${ }^{\mathbf{7 5}, \mathbf{7 6}}$.
The extract CS significantly reduced the oxidative damage caused by CCL4 and altered the normal range of hematological parameters which may be due to its stimulatory action on antioxidative enzymes through significantly increasing in $\mathrm{RBC}$ counts, $\mathrm{Hb}$ concentration, palatelete counts and WBC counts by $28.07 \%, 32.4 \%, 20.6 \%, 50.8 \%$ in combination group in comparison with positive group and by $26.3 \%, 27.9 \%, 15.6 \%, 44.2 \%$ in preventive group in comparison with positive group,by $21.05 \%, 15.3 \%, 11.3 \%, 31.1 \%$ in therapeutic group in comparison with positive group and by $15.7 \%, 6.8 \%$ $, 8.5 \%, 26.2 \%$ in silymarine group in comparison with positive group respectively.

8 observed that aqueous leaf extract of Cnidoscolus aconitifolius showed significantly reduced the damaging effects of $\mathrm{CCl} 4$ in the treated rats, by significantly increasing the $\mathrm{PCV}, \mathrm{RBC}, \mathrm{Hb}$, platelets, $\mathrm{MCV}$ and $\mathrm{MCH}$ values it may be due to the antioxidant properties of the extract, because Vitamin E and other free radical scavengers such as black tea have been reported to reduce the toxic effects of $\mathrm{CCl} 4$, especially on the liver ${ }^{\mathbf{6 5}}$.

Moreover ${ }^{77}$ found that acetone extract of Rhodiola imbricate arhizome against paracetamol induced liver toxicity in rats significantly increase hematological parameters (RBC, Hb, Platelete and WBC) which revealed that the extract is rich in these antioxidant compounds, which clearly support the antioxidant and other related pharmacological properties including hepatoprotective activity of Rhodiola .

The histological studies were carried basically to support the results obtained from serum enzymes assays ${ }^{29}$. The normal control rat liver showing normal central vein (star) with radiating cords of normal hepatocytes showing central uniform nuclei, and finely granular cytoplasm as shown in fig(6 a) also rat kidney from normal control group showing normal 
renal tubules lined by single layer of cuboidal epithelium as shown in fig (7a)

Positive control group of rat liver showing dilated congested hepatic sinusoids early hepatocellualr dysplasia with nuclear pleomorphism and hyperchromasia, with occasional binucleation of hepatocytes as shown in fig(6b), rat kidney from the positive control group showing diffusely infiltrating chronic non-specific inflammatory cellular infiltrates mainly lymphocytes as shown in fig(7b).

This is in agreement with ${ }^{\mathbf{5 6}}$ who stated that histopathological studies showed that CCL4 caused cytoplasmic vacuolization of centrolobular hepatocytes associated with leucocytic cells infiltration and kupffer cells activation. However, kidneys of rat revealed vacuolization of endothelial lining glomerular tufts as well as epithelial lining renal tubule. ${ }^{29}$ stated that the liver of CCL4 intoxicated rats showed massive fatty changes gross necrosis, broad infiltration of lymphocyte and kupffer cells around the central vein and loss of cellular bounderies. $^{46}$ reported that $\mathrm{CCl} 4$ caused a significant damage to renal structure, manifested as marked glomeruli and tubular damages probably due to the generation of ROS. So, hydroperoxides accumulated in kidney could cause cytotoxicity associated with membrane phospholipids peroxidation, the basis for renal damage and necrotic renal cells. In addition, the vasoconstriction that induced by $\mathrm{CCl} 4$ produced a local ischemic environment aggravates cellular damages ${ }^{62}$ However, CCl4 intoxication also altered the proximal tubular epithelial cells, mitochondria and lysosomes. The later released their contents into the tubular lumen with concomitant tubular damage ${ }^{\mathbf{7 8}}$. For combination rats group, as a whole, the liver tissue showed to a large extent a normal appearance reflected by slightly dilated central veins with normal liver cords and sinusoids as shown in fig(6c), rat kidney from the combined group showing normal renal tubules lined by single layer of cuboidal epithelium with rounded uniform nuclei as shown in fig(7c). For preventive group rat liver showing slightly dilated hepatic sinusoids), normal hepatocytes, as shown in fig(6d) ; rat kidney from the preventive group showing normal renal cortex with normal glomerulus (arrow) with normal capillary tufts, and surrounded by normal renal tubules, as shown in fig(7d). For therapeutic group rat liver showing dilated portal tract with mild portal fibrosis surrounded by normal hepatocytes, as shown in fig (6e) rat kidney from the therapeutic group showing renal medulla with normal renal tubules and mild interstitial inflammation, as shown in fig (7e). For silymarine group rat liver showing dilated congested hepatic sinusoids, and areas of hemorrhage, as shown in fig(6f), rat kidney from the sylimarin treated group showing renal medulla with near normal renal tubules apart from mild cloudy swelling of renal tubular epithelium, as shown in fig (7f) . Thus from obvious results CS extract show enhancement in the histology of the liver and modulate the histology features of the kidney. This is in agreement With ${ }^{\mathbf{5 6}}$ who stated that CS showed slightly improvement in hepatocytes and fatty changes in liver tissue and also showed improvement of the histological structure of the kidney. ${ }^{29}$ revealed that the histopathological observations of the liver rats pretreated with CS and subsequently given CCL4 showed more or less normal architecture of the liver having reversed to a large extent, the hepatic lesions produced by the toxins, almost comparable to the normal control and silymarine group because of containing antioxidant properties that may enhance the liver condition.

The hepatorenal activity of CS against $\mathrm{CCl} 4$ as manifested from our data is attributed to various mechanisms; primarily, its antioxidant activity whichresults from the polyphenolic constituents in CS. Polyphenols of CS act 
as anti peroxidative agents for the prevention of oxidative damage in living systems ${ }^{79}$. CS via its antioxidant activity quenches ROS produced byCCl4, reserves antioxidant enzymes and restores their levels ,improvement the histological structure of both liver and kidney and suppressing proliferation of liver and induced apptosis in HSCs .

\section{CONCLUSION}

It could be concluded from the present results that, $\mathrm{CCl} 4$ intoxication considerably damaged both the liver and kidneys depleted the antioxidant enzymes. CS antagonized CCl4-induced acute hepatotoxicity as evidenced by restoration of the liver function enzymes and indicators of acute liver damage by conserving the endogenous antioxidant mechanism and scavenging free radicals and enhancement of the reduction in malondialdehyde. This study thus provides evidence that CS may be an alternative treatment for liver diseases caused by xenobiotics. Also CS may protect against microcytic hypochromic anaemia, thrombocytopenia and stress associated with $\mathrm{CCl} 4$ administration in rats and reduce the hepatic damage in extrahepatic cholestasis by prevention of the oxidative stress, and the inflammatory process . As a result, CS as well as the reference drug silymarin enriched in phenolic compounds can protect humans against nephrotoxicity and hepatotoxicity induced by various xenobiotics and help maintain healthy liver and kidneys.

\section{Acknowledgement}

We acknowledge Prof. Dr. Samih Ibrahim El Dahmy , Department of Pharmacognosy and Medicinal Plants, Faculty of Pharmacy, Zagazig University for performance and Interpretation of the Phytochemical work.

\section{REFERENCES}

1. Rajesh, M.G. and Latha, M.S. (2004): Protective effects Glycyrhiza glibra linn on carbon tetrachloride induced peroxidative damage. Ind. J. Pharmacy., 36: 254 -256.

2. Notas, G., Kisseleva, T. and Brenner, D. (2009): NK and NKR cells in liver injury and fibrosis. Clinical Immunology., 130: 16-26.

3. Jaeschke, H., Me-Gill, M.R. and Ramachandran, A. (2012): Oxidant stress mitochondria and cell death mechanism in drug induced liver injury: Lessons learned from acetaminophen hepatotoxicity. Drug Metab., Rev., 44: 88-106.

4. Douhri, B. Idaomar, M. Skalisenhaji, N. Ennabili , A. and Abrini ,J. (2014): Hepatoprotective effect of origanumelongatum against carbon tetrachloride (ccl4) induced toxicity in rats. European Journal of Medicinal Plants., 4(1) 14-28

5. Ozturk, F., Ucar, M. Ozturk, I.C. Vardi, N. and Batcioglu, K. (2003):Carbon tetrachloride induced nephrotoxicity and protective effect of beta Carotene in Spragu-Dawely rats. Urology, 62: 353-356.

6. Akni, M., Chtourou, Y. and Garoui, E.M. (2012):Carbon tetrachloride induced nephrotoxicity and DNA damage in rats: Protective role of vanillin. Human and Experimental Toxicology., 31: 844-885.

7. Hermenean, A., Ardelean, A., Stan, M., Herman, H. Mihali, C.V. Costache, M. and Dinischiotu, A. (2013):Protective effects of naringenin on carbon tetrachloride induced acute nephrotoxicity in mouse kidney Chemico. Biologyical Interactions., 206: 138-147.

8. Saba, A.B., Oyagbemi, A.A. and Azeez, O.I. (2010):Amelioration of carbon tetrachloride-induced hepatotoxicity and haemotoxicity by aqueous leaf extract of Cnidoscolus aconitifolius in rats Nig. J. Physiol. Sci., 25: 139 -147.

9. Oqeturk, M., Kus, I. Pekmez, H. Yekeler, H. Sahin, S. and Sarsilmaz, M. (2008):Inhibition of 
carbon tetrachloride -mediated apoptosis and oxidative stress by melatonin in experimental liver fibrosis. Toxical. Ind. Health., 24: 201-208.

10. Kaneko, M., Nagamine, T. Nakazato, K. and Mori, (2013): Theantiapoptotic effect of fucoxanthin on carbon tetcachloride - induledd hepatotoxicit. J. Toxicol. Sci., 38: 115125.

11. Zhao, X., Song, J.L., Kil, J.H. and Park, K.Y. (2013): Bamboo salt attenuates $\mathrm{CCl} 4$ hepatic damage Sprague-Dawely rat. Nut. Res. Pract., 7: 273-280.

12. Ai, G., Liu, Q. Hua, W. Huang, Z. and Wang, D. (2013):Hepatoprotective evaluation of total flavonoids extract from flowers of Abdelmoschus manihot (L.).Medicai., 146: 794-80.

13. Ali, S.A. and Hamed, M.A. (2006):Effect of Ailanthus altissima and Zizyphus spina Christi on bilharzial infestation in mice: histological and histopathological Studies. J Applied Sci., 6: 1437-1446.

14. Ali, S.A., El-Rigal, N. and Rizk, M.Z. (2006): Nutritional supplementation with Ailanthus altissimia and Ziziphus spina Christi to compensate for some metabolic disorders in Schistosoma mansoni infected mice.Pak J Biol Sc., 9: 1700-1706.

15. El-Ansary, A.K., Ahmed, S.A. and Aly S.A. (2007): Antischistosomal and liver protective effects of Curcuma longa extract in Schistosoma mansoni infected mice. Indian J. Exp. Biol., 45: 791-801.

16. Mitra, S.K., Seshadri, S.J. and Venkataranganna, M.V. (2000):Effectof HD-03-a herbal formulation in galactosamine-induced hepatopathy in rats. Ind. J. Physiol. Pharm., 44: 82-86.

17. Bajpai, M., Mishra, A. and Prakash, D. (2005): Antioxidant and free radical scavenging activities of some leafy
vegetables.Int. J. Food Sci. Nutr., 56:73-81.

18. Kurian, J.C. (2003):Coriandrum sativum, Plants that Heal, fifth ed. Oriental Watchman Publishing House, Pune. India, 15:192-195.

19. Khare, C.P. (2004): Antioxidant and Phytochemicals on Herbs. Encyclopedia of Indian Medicinal Plants, 9: 162-167.

20. Deepa, B. and Anuradha, C.V. (2011):Antioxidant potential of Coriandrum Sativum L.seed extract. Indian J. Exp. Biol., 49: 30-38.

21. Chithra, V. and Leelamma, $\mathbf{S}$. (2000):Coriandrum sativum effect on lipid metabolism in 1,2-dimethyl hydrazine induced colon cancer. $\mathrm{J}$. Ethnopharm.,71: 457-463.

22. Fujita, K. (2004): Antioxidant activity of coriander volatile compounds against salmonella choleraesteis. J. Agri. Food Chem., 4: 3329-3332.

23. Tanabe, H., Yoshida, M. and Tomita, N. (2002): Comparison of the antioxidant activities of 22 commonly used herbs and spices on the lipid oxidation of pork meat. Anim. Sci. J., 73: 389-393.

24. Letteron, P., Labbe, G. and Degott, C. (1990):Mechanism for the protective effects of silymarin against carbon tetrachloride-induced lipid peroxidation and hepatotoxicity in mice: evidence that silymarin acts both as an inhibitor of metabolic activation and as a chain-breaking antioxidant. Biochem Pharmacol., 39: 2027-2034.

25. Katiyar, S.K., Roy, A.M. and Baliga, M.S. (2005):Silymarin induces apoptosis primarily through a p53dependent pathway involving Bcl2/Bax, cytochrome c release, and caspase activation. Mol Cancer Ther., 4: 207-216.

26. Kil, H.Y., Seong, E.S. Ghimire, B.K. Chung, I.M. Kwon, S.S. Goh, E.J. Hoe, K. Kim, M.J. Lim, J.D. Lee, D. and Yu, C.Y. (2009):Antioxidant and antimicrobial activities of crude 
sorghum extract.Food Chemistry, 115: 1234-1239.

27. Nambiar, V., Mehta, R. and Daniel, M. (2005):Polyphenol content of three Indian Green Leafy vegetables. J Food Science and Technol., 42(6): 503-505.

28. Nambiar,V.S., Danial, M. and Guin, P.(2010): Characterization of polyphenols from coriander leaves (coriandrum sativum), red amaranthus (A.Paniculatus) and green amaranthus (A.Frumentaceus) using paper chromatography: and their health implications . Herbal Medicine and Toxicology 4 (1) 173-177 .

29. Sreelatha, S., Padma, P.R. and Umdevi, M. (2009):Protective effects of Corindrum sativum extracts on carbon tetrachloride induced hepatotoxicity in rats. food and Chemical Toxicology., 47: 702-708.

30. Ashokshnoy,K., Somayaji, S.N. and Bairy, K.L. (2001): Hepatoprotective effects of ginkgo biloba against carbon tetrachloride induced hepatic injury in rats.India journal of pharmacology., 33: 260-266.

31. Young D.S. (2001): Effect of disease on clinical lab. Tests, 4th ed. AACC press.

32. Varely, H. (1994): PracticalClinical Biochemistry, 5th ed. Vol. I, William Heinemann Medical Books Ltd, London, pp. 601.

33. Satoh, K (1978):Serum lipid peroxide in cerebrovascular disorders determined by a new colorimetric method. Clinic Chimica Acta., 90: 3743.

34. Rohrdanz, E., Ohler, S. Tran-Thi, W.H. and Kahl, R. (2002): The phytoestrogen daidzen effects the antioxidant enzyme system of rat hepatoma Hells cells. J. Nutr., 13: 370-375.

35. Xu,J.Y., Su Y.Y., Cheng, J.S., Li , S. X ., Liu, R., Li,W.X., Xu G.T. and li ,q.n. (2010): Protective effects of fullerenol on carbon tetrachlorideinduced acute hepatotoxicity and nephrotoxicity in rats.

Carbon.,48:1388-1396.

36. Levesque, R. (2007): Programming and Data Management :A Guide for SPSS and SAS Users, Fourth Edition SPSS Inc. ChicagoIII.

37. Kassem, S. S., Abdel-Kader, M. M. Al-Sayed, E.M. El-Din, S. ElHawary, M.H.A. Z. and Haggag, M. M. (2014):Modulatoryeffects of aerial parts of Coriandrum sativum L. on carbon-tetrachlorid induced hepatorenal toxicity. Global Veterinaria, 12 (4): 523-531.

38. Patel, D.K., Desal, S.N., Gandhi, H.P., Devkar, R.V. and Ramachandran, A.V. (2012):Cardioprotectiveeffects of Coriandrum sativum L.on isoproternol induced myocordial necrosis in rats. Food Chemtoxicol., 50: 3120-3125.

39. Ottu, O.J., Atawodi, S.E. and Onyike, E. (2013):Antioxidant, hepatoprotective effects of methanolic root extract of Cassia singueana in rats following acute and chronic carbontetrachloride intoxication. Asian Pac. J. Trop. Med., 6: 609 - 615.

40. Sreelatha, S. and Inbavalli, R. (2012):Antioxidant,

antihyperglycemic and antihyperlipidemic effects of Coriandrum sativum leaf and stem in alloxan - induced diabetic rats. J. Food Sci., 77: 119-123.

41. Melo, E.D., Filho, J.M. and Guerra, M.B. (2005):Characterization of antioxidant compounds in aqueous coriander extract (Coriandrum stivum L.). Lebensmittel Wissenschaft undTechonlogic., 38: 15-19.

42. Middleton, E.J.R., Kandaswami, C. and Theoharides, T.C. (2000): The effects of palnt flavonoids on mammalian cells:implications for inflammation, heart disease and cancer. Pharmacol. Rev., 52:673-751.

43. Rohrdanz, E., Ohler, S. Tran-Thi, W.H. and Kahl, R. (2002): The phytoestrogen daidzen effects the 
antioxidant enzyme system of rat hepatoma Hells cells. J. Nutr., 13: 370-375.

44. Zuber, R., Modriansky, M., Dvorak, Z., et al., (2002):Effect of silybin and its congeners on human liver microsomal cytochrome P450 activities. Phytother. Res. 16, 632638.

45. Doehmer, J., Tewesa, B. and Klein, K.U. (2008):Assessment of drug-drug interaction for silymarin. Toxicol. in Vitro 22: 610-617.

46. Makni, M., Chtourou, Y. and Garoui, E.M. (2013):Carbontetrachloride-induce nephrotoxicity and DNA damage in rats. Protective role of vanillin. Human and Experimental. Toxicol., 31: 844852.

47. Hollman, P. C., Hertog, M.G. and Katan, M.B. (1996):Role of dietary flavonoids in protection against cancer and coronary heart disease. Biochem. Soc. Trans., 24: 785-9.

48. Green, M ., Pragada, R.R. Ethadi, S.and Rajanna, B. (2013):

Comparative study on some selected species of ocimum genus on free radical scavenging activity and hepatoprotective activity against ccl4 induced intoxication in rats.American Journal of Molecular Biology., 3:183186

49. Ghada, M.A.R., Ezzeldeen, S.E. Aziza, M.H. Sekena, H.A. Nabila, S.H. Fathia, A.M. and Mosaad, A.A. (2013):Grape (Vitis vinifera) seed extract inhibits the cytotoxicity and oxidative stress in liver of rats treated with carbon tetrachloride. Global Journal of Pharmacology, 7 (3): 258269.

50. Nyblom, H., Berggren, U. Balldin,J. and Olsson, R. (2004): High AST/ALT ratio may indicate advanced alcoholic liver disease rather than heavy drinking. Alcohol Alcoholism, 39(4): 336-339.
51. Ahmed, B., Khan, S.A. and Alam, T. (2003):Synthesis and antihepatotoxic activity of some heterocyclic compounds containing the 1, 4dioxane ring system.Pharmazie., 58: 173-176.

52. Kang, J.S., Jeon, Y.J. Park, S.K. Yang, K.H. and Kim, H.M. (2004):Protection against lipopolysaccharide-induced sepsis and inhibition of interleukin-1 beta and prostaglandin E2 synthesis by silymarin. Biochem Pharmacol., 67: 175-181.

53. Shukla, A. and Bhatia, S.J. (2010):Outcome of patients with primary hepatic venous obstruction treated with anticoagulants alone. Indian J. Gastroenterol., 29: 8-11.

54. Fahmyi, H.A., Shreifi, N.H. and Gharibi, O.A. (2014): The protective effect of Coriandium sativum extract on hepato-renal toxicity induced in irradiated rats. European Journal of Medicinal Plants, 4(3): .

55. Vaca, C.E., Wilhelm, J.M. and Harms-Rihsdahl, M. (1988):Interaction of lipid peroxidation product with DNA. Mutat. Res. Rev. Gen. Toxicol., 195: 137-149.

56. Haggag, M.H., (2011):Protective effect of Coriandrum sativum plant of hepatotoxicity and nephrotoxicity induced by carbon tetrachloride in male albino rats. In 'The 6 Arab and 3 International Annual Scientific Conference on: Development of Higher Specific Education Programs in Egypt and the Arab World in the Light of Knowledge Era Requirements'. pp: 2332-2348.

57. El-Denshary, E.S., Al-Gahazali, M.A. Mannaa, F.A. Salem, H.S., Hassan, N.S. and Abdel-Wahhab, M.A. (2012):Dietary honey and ginseng protect against carbon tetrachloride-induced hepatonephrotoxicityin rats. Exper. Toxicol. Pathol., 64: 753-760. 
58. Sarhan, N.A., El-Denshary, E.S. Hassan, N.S. Abou-Salem, F.M. and Abdel-Wahhab, M.A. (2012):Isoflavones-Enriched soy protein prevents CCL4- induced hepatotoxicity in rats. ISRN Pharmacol. 347930. Epub 2012 Mar.1.

59. Schinella, G.R. Tournier, H.A. Prieto, J.M. Mordujovich, D.B.P. and Rios, J.L. (2002): Antioxidant activity of anti-inflammatory plant extracts. Life Sci., 18: 1023-1033.

60. Bhattacharjee, R. and Sil, P.C. (200): Protien isolate from herb, phyllanthus niruril. (euphorbiaceae), plays hepatoprotective role against carbon tetrachloride induced liver damage via its antioxidant properties. 7Food Chem. Toxicol., 45: 817-826.

61. Abdel-Wahhab, M.A., Ibrahim, A.A. El-Nekeety, A.A. Hassan, N.S.and Mohamed, A.A. (2012):Panax ginseng C.A. Meyer extract counteracts the oxidative stress in rats fed multi-mycotoxins contaminated diet.Comunicata Scientiae, 3(3): 143-153.

62. Khan, R.A., Khan, M.R. Sahreen, S. and Ahmed, M. (2012):Evaluation of phenolic contents and antioxidant activity of various solvent extracts of Sonchus asper (L.) Hill. Chemistry Central Journal, 6: 12.

63. Hu, J., Lee, S.O., Hendrich, S.and Murphy, P.A. (2002):Quantification of the group B soyasaponins by highperformance liquid chromatography. Journal of Agricultural and Food Chemistry, 50:87-94.

64. Ramadan, M.F. and Morsel, J.T. (2004):Oil goldenberry (Physalis peruviana L.). Journal of Agriculture and Food Chemistry, 51: 969-974.

65. Weber, L.W.D., Boll, M. and Stampfl, A. (2003):Hepatotoxicityand Mechanism of Action of Haloalkanes: Carbon Tetrachloride as a Toxicological Model. Critical Reviews in Toxicology, 33 (2): 105-136.
66. Pradhan, S.C. and Girish, C. (2006):Hepatoprotective herbal drug, silymarin from experimental pharmacology to clinical medicine. Indian J Med Res., 124: 491-504.

67. Rathee, P., Chaudhary, H. Rathee, S. Rathee, D. Kumar, V. and Kohli, K. (2009):Mechanismof action of flavonoids as anti-inflammatory agents: a review. Inflamm. Allergy Drug Targets, 8(3): 229-235.

68. Moon, E.Y. and Pyo, S., (2000): AflatoxinB1 inhibits CD14-mediated nitric oxide production in murine peritoneal macrophages. Int. J. Immunopharmacol. 22(3): 237-246.

69. Azeredo, A.K., Lortz, S. Lenzen, S. Curi, R. Eizirik, D.L. and Tiedge, M. (2003):Improvement of the mitochondrial antioxidant defense status prevents cytokine induced nuclear factor-kappa B activation in insulin-producing cells.Diabetes, 52: 93-101.

70. Bartosz, G. (2009): Reactive oxygen species: destroyers or messengers? Biochem. Pharmacol. 77(8): 13031315.

71. Omura, O. (1998): Chelation of mercury and other heavy metals. Acupunct. Electrother. Res., (21) 2: 133-6.

72. Moritz, R.P. and Pankow, D. (1989):Effect of carbon tetrachloride and chloroform on hematologic parameters in rats Folia. Haematol. Int. Mag. Klin. Morphol. Blutforsch., 116 (2): 283-287.

73. Travlos, G.S., Morris, R.W. Elwell, M.R. Duke, A. Rosenblum, S. and Thompson, M.B. (1996):Frequency and Rela-tionships of Clinical Chemistry and Liver and Kidney Histopathology Findings in 13-Week Toxicity Studies in Rats. Toxicology, 107 (1): 17-29.

74. Droge, W. (2002): Free radicals in the physiological control of cells. Physiol. Rev., 82: 47-95. 
75. Cines, D.B and Lanchette, V.S. (2003):Immune thrombocytopenia purpura. N Engl J Med2002; 346: 9951008.

76.

Giannini, $\quad$ E.G. (2006): Thrombocytopeniain chronic liver disease and pharmacologic treatment options. Aliment.Pharmacol. Ther.,23: 1055-1065.

77. Senthilkumar , R., Chandran, R . and Parimelazhagan T. (2014):

Hepatoprotective effect of Rhodiola imbricata rhizome against paracetamol-induced liver toxicity in rats, Saudi Journal of Biological Sciences, (14)00035-7 :S1319-562X.

78. Green, M ., Pragada, R.R. Ethadi, S.and Rajanna, B. (2013):

Comparative study on some selected species of ocimum genus on free radical scavenging activity and hepatoprotective activity against ccl4 induced intoxication in rats.American Journal of Molecular Biology., 3:183186

79. Wong, P.Y. and Kitts, D.D.

(2006): Studieson the dual antioxidant and antibacterial properties of parsley (Petroselinum crispum) and cilantro (Coriandrum sativum) extracts. Food Chem., 97: 505-515 
Table 1 : Polyphenol content of coriander leaves

\begin{tabular}{|l|c|}
\hline \multicolumn{1}{|c|}{ Name of the compounds } & Coriander leaves \\
\hline Apigenin & - \\
\hline 3',4'-di-OMe luteolin & - \\
\hline Kaempferol & - \\
\hline 4'-OMe kaempferol & - \\
\hline 7'4'-di-OMe kaempferol & + \\
\hline Quercetin & + \\
\hline 3'-OMe quercetin & + \\
\hline 4'-OMe quercetin & - \\
\hline 3',4'-di-OMe quercetin & + \\
\hline Acacetin & - \\
\hline Gossypetin & - \\
\hline Quercetagetin & - \\
\hline Proanthocyanidins & - \\
\hline Anthocyanins & - \\
\hline Coumarins & - \\
\hline
\end{tabular}

$+:$ Present; - : Absen

Table 2 : Phenolic acids content of coriander leaves

\begin{tabular}{|l|c|}
\hline Name of the compounds & Coriander leaves \\
\hline Vanillic acid & + \\
\hline Syringic acid & - \\
\hline p-OH benzoic acid & - \\
\hline Melilotic acid & - \\
\hline Gentisic acid & - \\
\hline o-Coumaric acid & - \\
\hline p-Coumaric acid & + \\
\hline Cis-Ferulic acid & + \\
\hline Trans-Ferulic acid & + \\
\hline Phloretic acid & - \\
\hline Chlorogenic acid & - \\
\hline Resorcylic acid & - \\
\hline
\end{tabular}

$+:$ Present ; - : Absent 
Table 3: Effect of coriander leaves extract on some biochemical parameters in hepatotoxicity produced by CCL4 in rats .

\begin{tabular}{|l|c|c|c|c|c|}
\hline & ALT $(\mathrm{U} / \mathrm{ml})$ & AST $(\mathrm{U} / \mathrm{ml})$ & Albumin $(\mathrm{mg} / \mathrm{dl})$ & $\mathrm{MDA}(\mathrm{nmol} / \mathrm{g})$ & $\mathrm{NO}(\mathrm{umol} / \mathrm{g})$ \\
\hline Negative control & $37.3 \pm 4.5$ & $99.5 \pm 9.7$ & $3.9 \pm 0.08$ & $31.4 \pm 14.5$ & $41.9 \pm 9.4$ \\
\hline Positive control & $105 \pm 9.3^{* \mathrm{a}}$ & $264.9 \pm 37^{* \mathrm{a}}$ & $2.7 \pm .4^{* \mathrm{a}}$ & $182.7 \pm 35.4^{* \mathrm{a}}$ & $79.2 \pm 4.5^{* \mathrm{a}}$ \\
\hline Combination & $50.8 \pm 3^{* \mathrm{~b}}$ & $128.3 \pm 6.4^{* \mathrm{~b}}$ & $3.6 \pm 0.1^{* \mathrm{~b}}$ & $49.4 \pm 4.8^{* \mathrm{~b}}$ & $49.8 \pm 4.2^{* \mathrm{~b}}$ \\
\hline$\%$ change & $51.6 \%$ & $51.1 \%$ & $33.3 \%$ & $72.9 \%$ & $59.03 \%$ \\
\hline Preventive & $54.8 \pm 7.8^{* \mathrm{~b}}$ & $149.4 \pm 7.2^{* \mathrm{~b}}$ & $3.4 \pm 0.1^{* \mathrm{~b}}$ & $61.9 \pm 4.9^{* \mathrm{~b}}$ & $60.9 \pm 1.8^{* \mathrm{~b}}$ \\
\hline$\%$ change & $43.04 \%$ & $43.6 \%$ & $25.9 \%$ & $66.1 \%$ & $30.04 \%$ \\
\hline Therapeutic & $75.4 \pm 0.4^{* \mathrm{~b}}$ & $180.4 \pm 14.3^{* \mathrm{~b}}$ & $3.2 \pm 0.1^{* \mathrm{~b}}$ & $91.6 \pm 8.4^{* \mathrm{~b}}$ & $68.3 \pm 4.0^{* \mathrm{~b}}$ \\
\hline$\%$ change & $30.09 \%$ & $31.8 \%^{*}$ & $18.5 \%$ & $49.8 \%$ & $15.95 \%$ \\
\hline Silymarin & $85.2 \pm 4.3^{* \mathrm{~b}}$ & $208.1 \pm 7.1^{* \mathrm{~b}}$ & $3.0 \pm 0.1^{* \mathrm{~b}}$ & $126.8 \pm 13.5^{* \mathrm{~b}}$ & $72.3 \pm 1.7^{* \mathrm{~b}}$ \\
\hline$\%$ change & $18.8 \%$ & $21.4 \%$ & $11.1 \%$ & $30.5 \%$ & $9 \%$ \\
\hline
\end{tabular}

Values are expressed as mean \pm S.E.

a: Values significantly differ from negative control group.

b: Values significantly differ from postive control group.

*: $\mathrm{P}<0.001$

$\%$ change: Values different from postive control group group.

Table 4: Effect of coriander leaves extract on some hematological parameters changes in experimentally induced hepatotoxicity in rats .

\begin{tabular}{|l|c|c|c|c|}
\hline & $\mathrm{WBC}\left(\mathrm{X} 10^{3}\right)$ & $\mathrm{RBC}\left(\mathrm{X} 10^{6}\right)$ & $\mathrm{PLT}\left(\mathrm{X} 10^{3}\right)$ & $\mathrm{Hb}(\mathrm{g} / \mathrm{dl})$ \\
\hline Negative control & $9.1 \pm 0.75$ & $7.7 \pm 1.1$ & $165.9 \pm 16$ & $14.3 \pm 1.1$ \\
\hline Positive control & $6.1 \pm 0.7^{* \mathrm{a}}$ & $5.7 \pm 0.5^{* \mathrm{a}}$ & $116.7 \pm 11.5^{* \mathrm{a}}$ & $11.1 \pm 1.6^{* \mathrm{a}}$ \\
\hline Combination & $9.2 \pm 0.7^{* \mathrm{~b}}$ & $7.3 \pm 0.9^{* \mathrm{~b}}$ & $140.8 \pm 14^{* \mathrm{~b}}$ & $14.7 \pm 1.3^{* \mathrm{~b}}$ \\
\hline$\%$ change & $50.8 \%$ & $28.07 \%$ & $20.6 \%$ & $32.4 \%$ \\
\hline Preventive & $8.7 \pm 0.7^{* \mathrm{~b}}$ & $7.2 \pm 0.76^{* \mathrm{~b}}$ & $135 \pm 9.9^{* \mathrm{~b}}$ & $14.2 \pm 1.6^{* \mathrm{~b}}$ \\
\hline \% change & $44.2 \%$ & $26.3 \%$ & $15.6 \%$ & $27.9 \%$ \\
\hline Therapeutic & $8 \pm 0.7^{* \mathrm{~b}}$ & $6.9 \pm 0.7^{* \mathrm{~b}}$ & $130 \pm 11.2^{* \mathrm{~b}}$ & $12.8 \pm .6^{* \mathrm{~b}}$ \\
\hline \% change & $31.1 \%$ & $21.05 \%$ & $11.3 \%$ & $15.3 \%$ \\
\hline Silymarin & $7.7 \pm 0.8^{* \mathrm{~b}}$ & $6.6 \pm 0.6^{* \mathrm{~b}}$ & $126.7 \pm 12.3^{* \mathrm{~b}}$ & $11.9 \pm 1.1^{* \mathrm{~b}}$ \\
\hline$\%$ change & $26.2 \%$ & $15.7 \%$ & $8.5 \%$ & $6.8 \%$ \\
\hline
\end{tabular}

Values are expressed as mean \pm S.E.

a: Values significantly differ from negative control group.

b: Values significantly differ from postive control group.

$*$ : $\mathrm{P}<0.001$

$\%$ change: Values different from postive control group. 

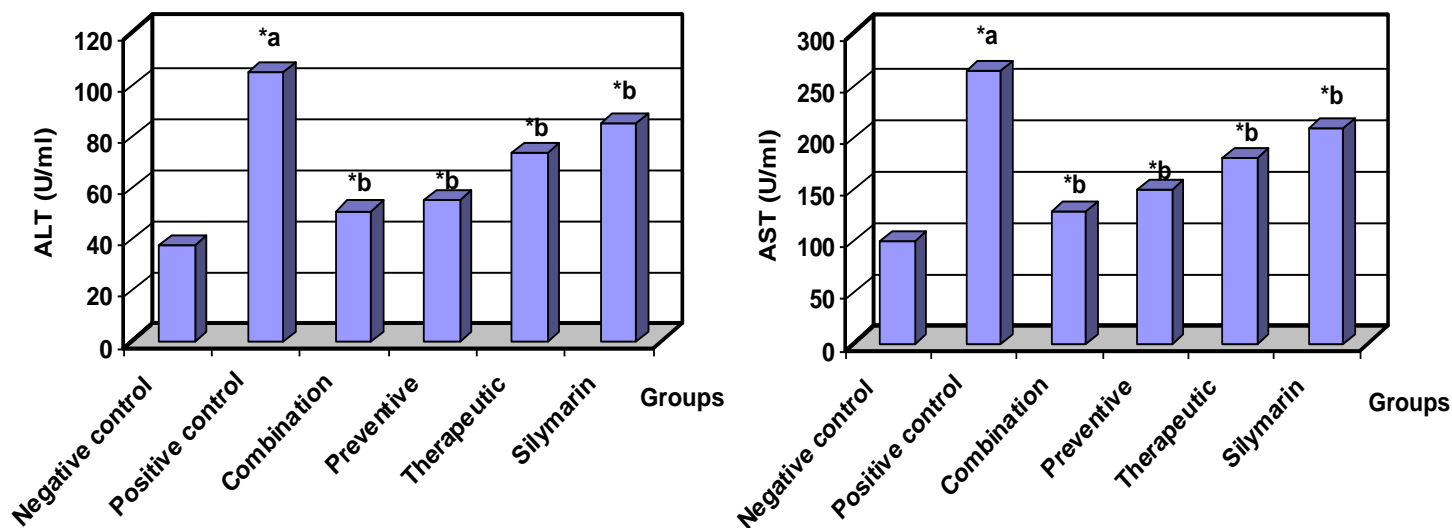

Graph 1: Relation between ALT level and all groups

Graph 2: Relation between AST level and all groups

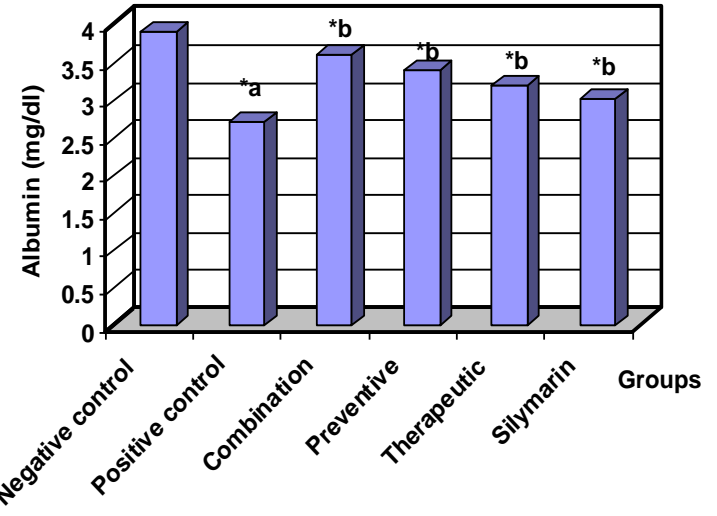

Graph 3: Relation between Albumin level and all groups

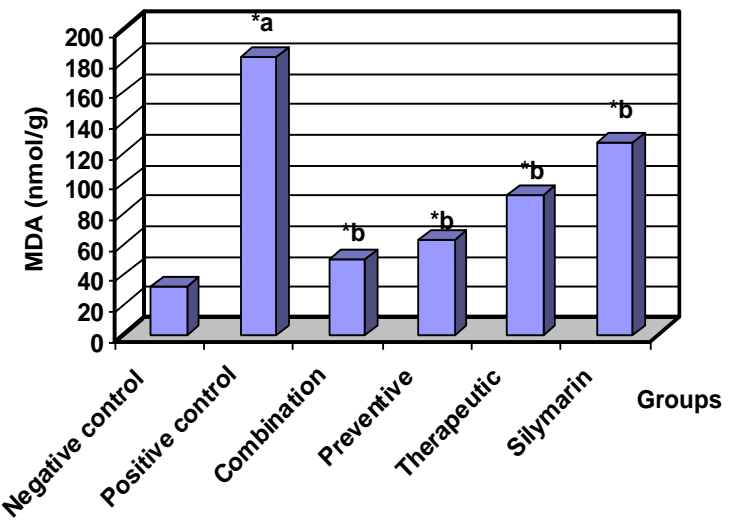

Graph 4: Relation between MDA level and all groups

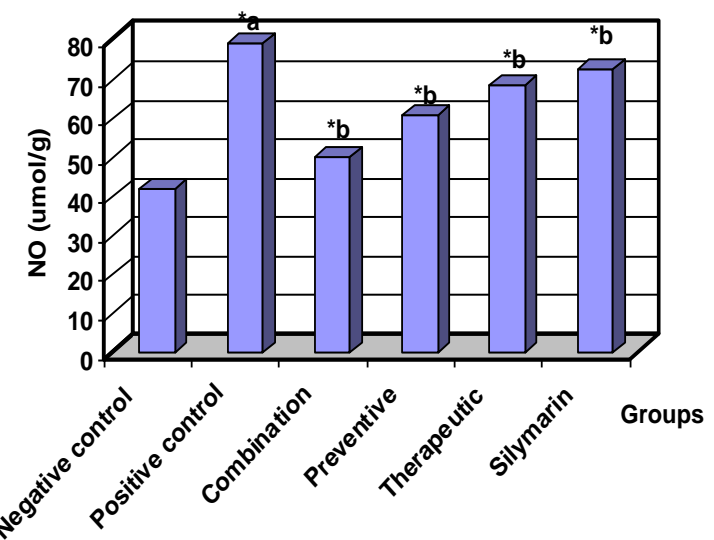

Graph 5:Relation between NO level and all groups 


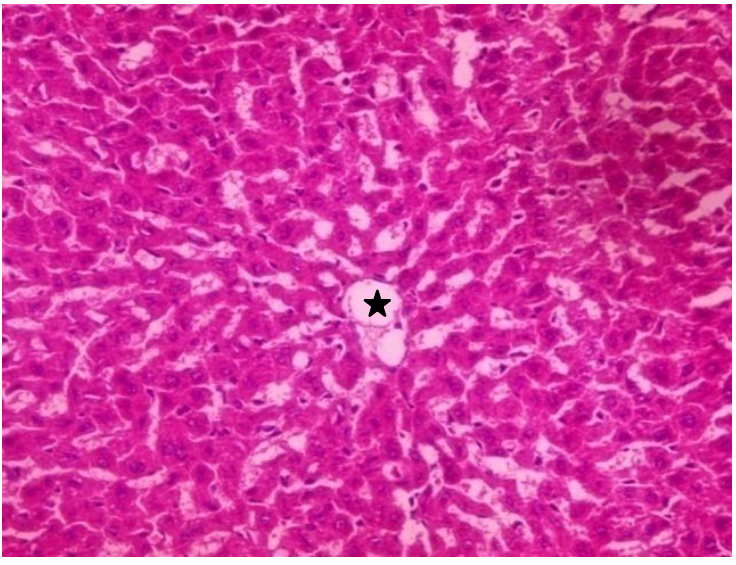

Fig. (6a): Photomicrograph of rat liver from negative control group, (H\&E,X 400).

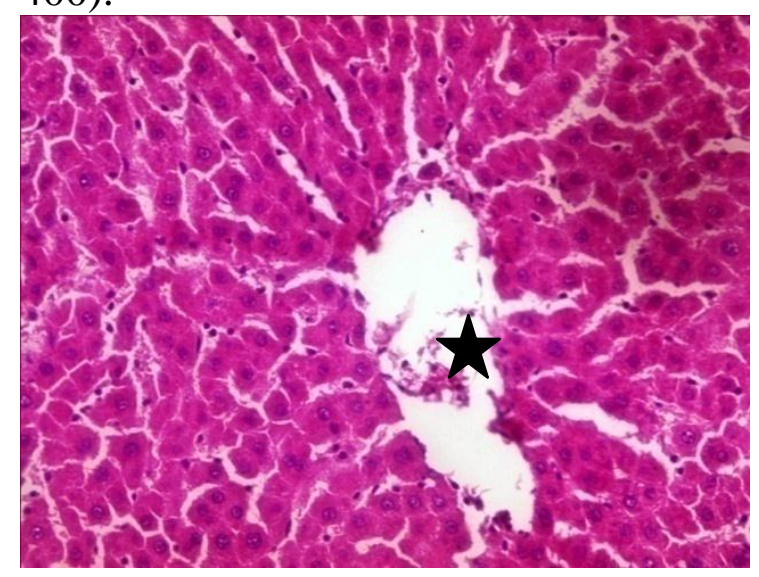

Fig. (6c): Photomicrograph of rat liver from the combined group, (H\&E,X 400).

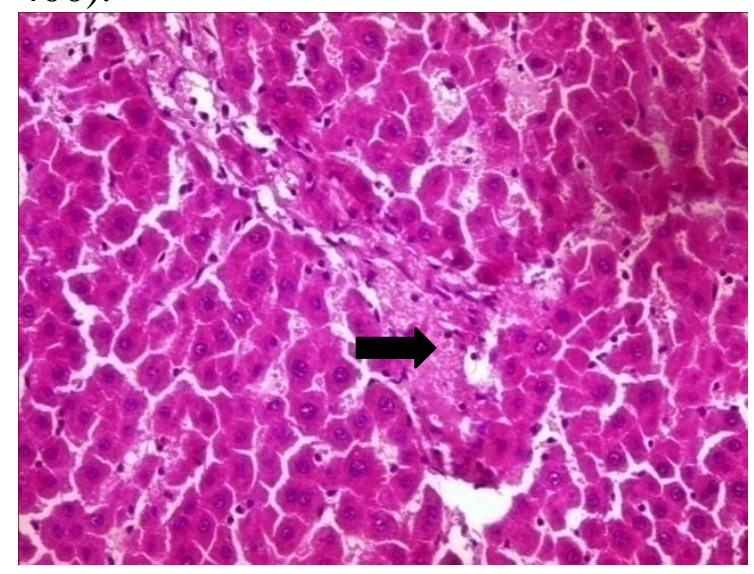

Fig. (6e): Photomicrograph of rat liver from the therapeutic group showing, (H\&E,X 400).

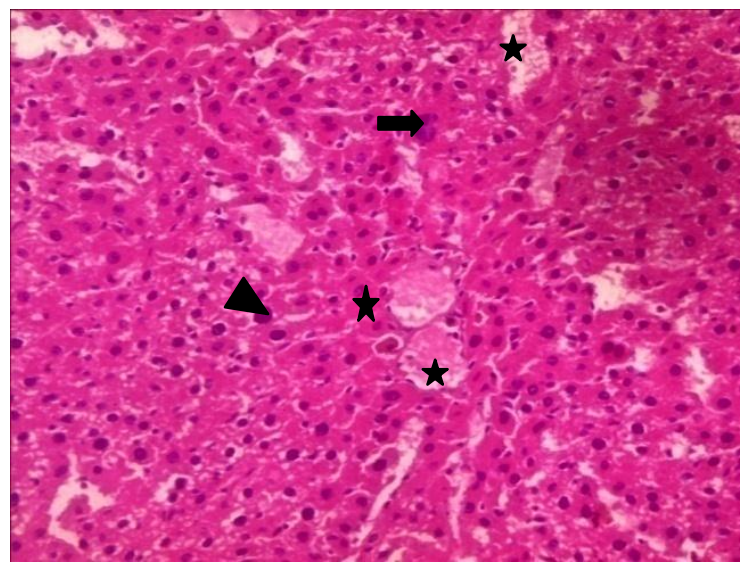

Fig. (6b): Photomicrograph of rat liver of positive control group, (H\&E, X 400)

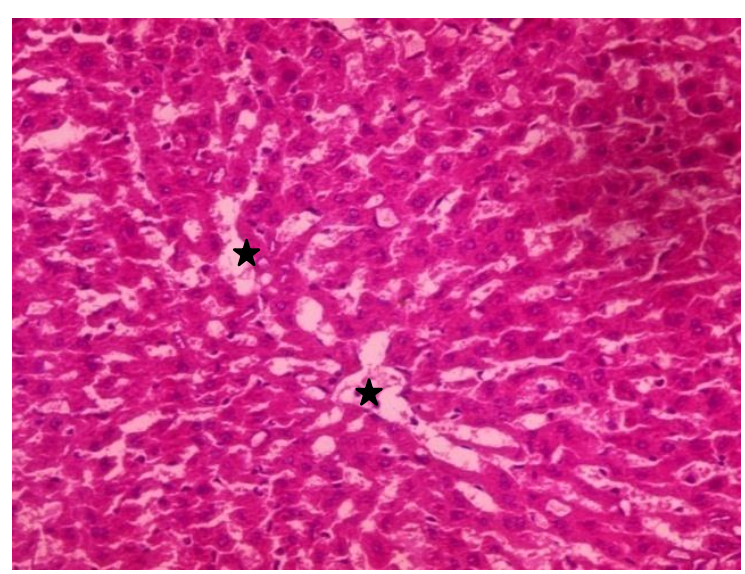

Fig. (6d): Photomicrograph of rat liver from the preventive group, (H\&E,X 400).

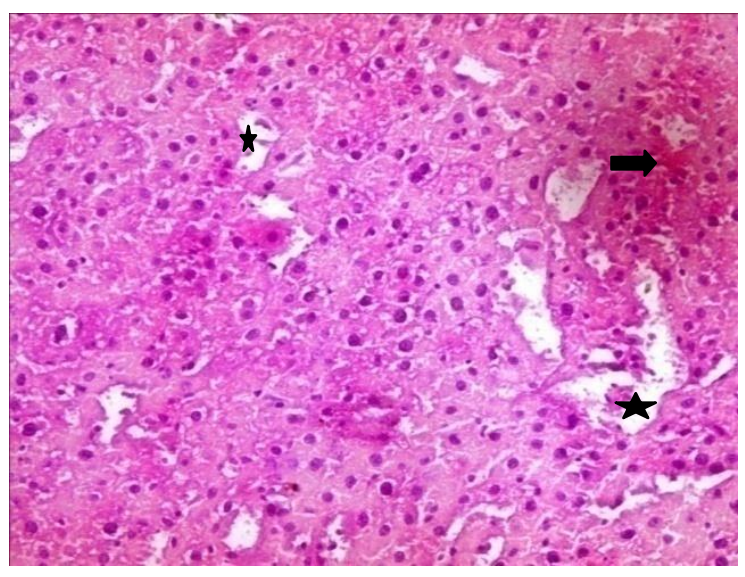

Fig. (6f): Photomicrograph of rat liver of sylimarine control group showing, (H\&E,X 400). 


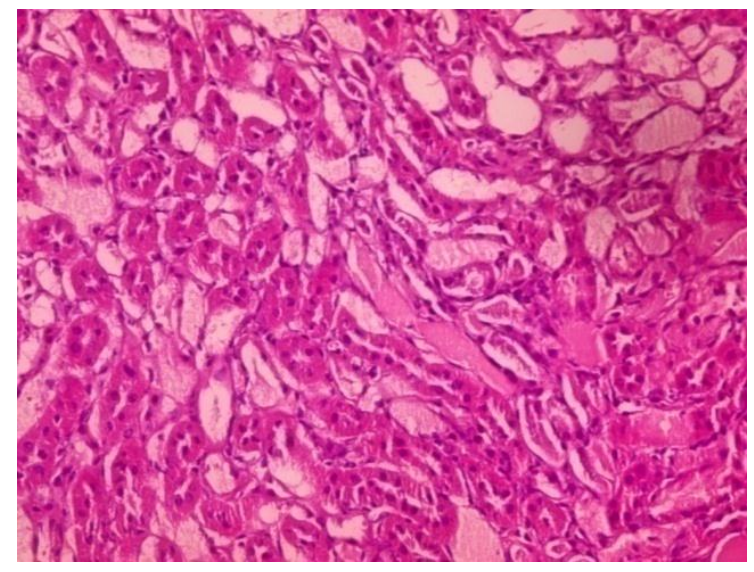

Fig. (7a): Photomicrograph of rat kidney from negative control group, (H\&E,X 400).

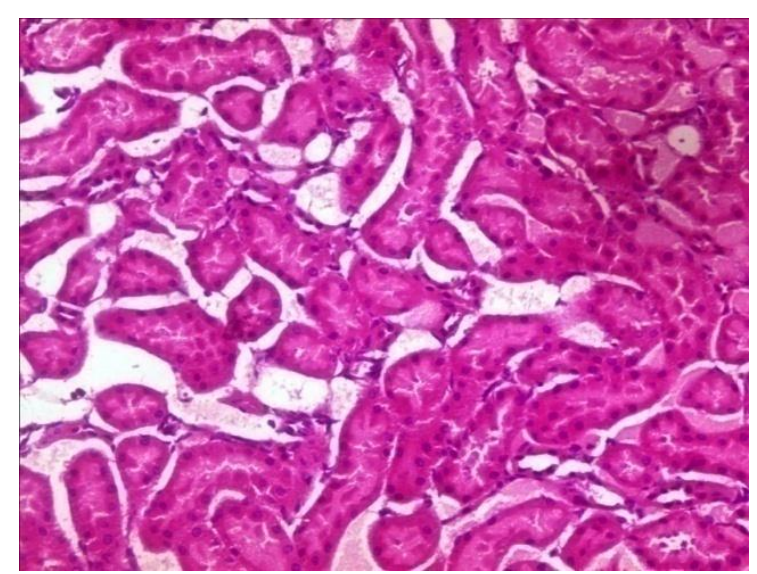

Fig. (7c): Photomicrograph of rat kidney from the combined group, (H\&E,X 400).

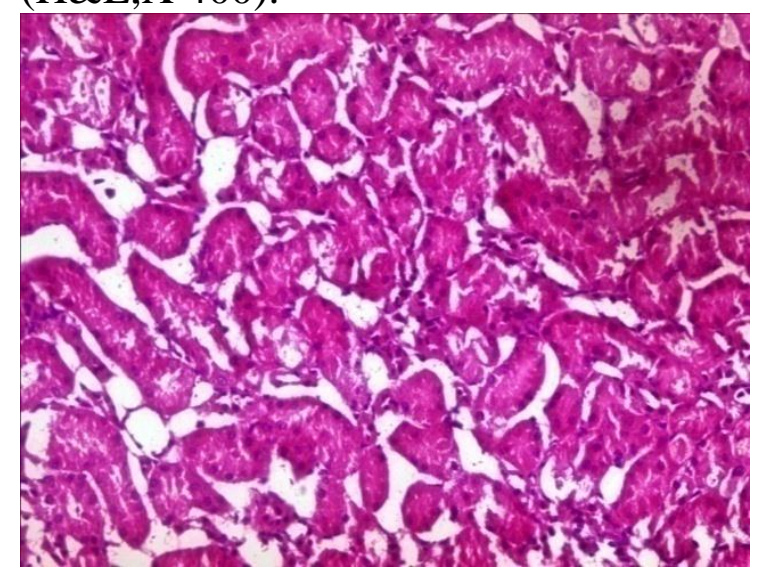

Fig. (7e): Photomicrograph of rat kidney from the therapeutic group, (H\&E,X 400).

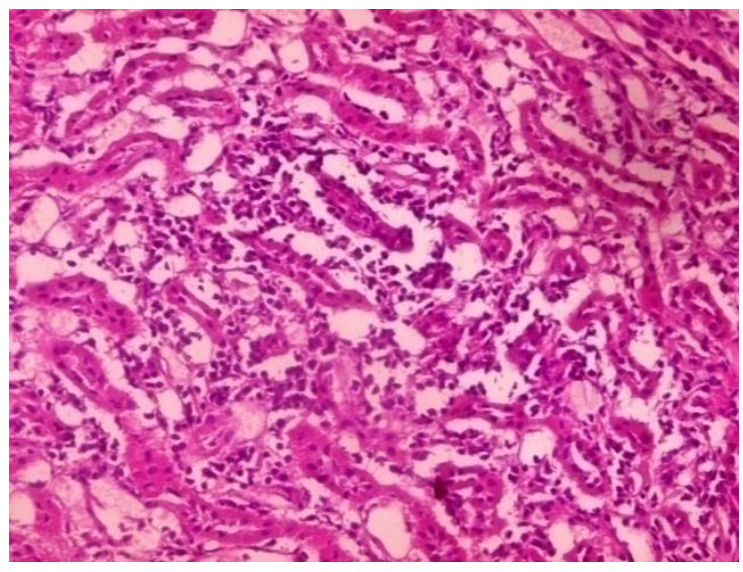

Fig. (7b): Photomicrograph of rat kidney from the positive control group, (H\&E,X 400).

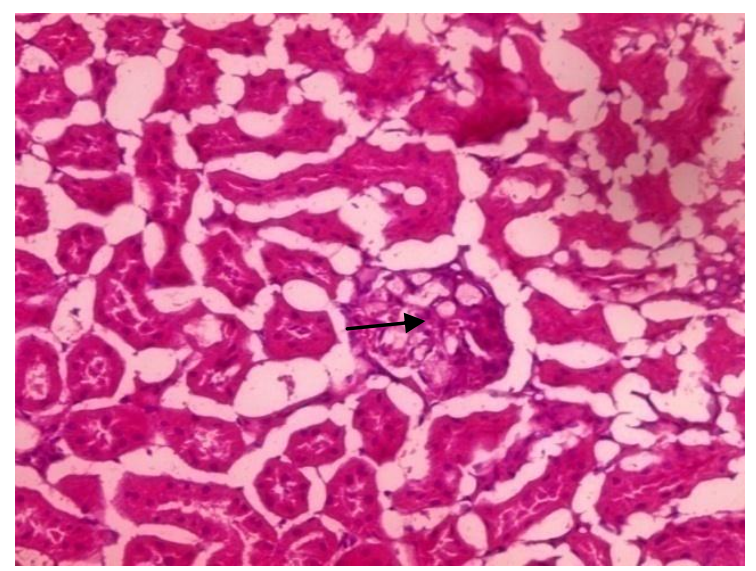

Fig. (7d): Photomicrograph of rat kidney from the preventive group, (H\&E, X 400).

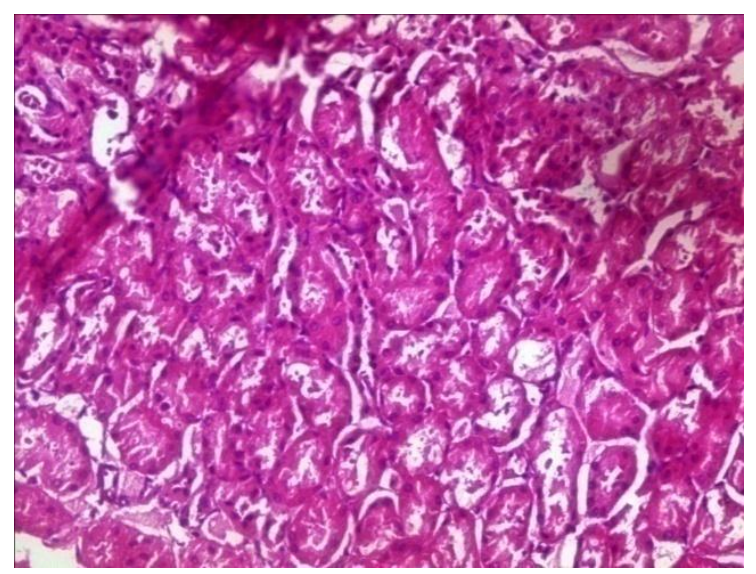

Fig. (7f): Photomicrograph of rat kidney from the sylimarin group, $(\mathrm{H} \& \mathrm{E}, \mathrm{X} 400)$. 